\title{
$\underline{\text { Remote Monitoring in Heart Failure }}$
}

Michael P Frenneaux; Nicholas D Gollop ${ }^{1}$; Brodie L Loudon'; Sathish Parasuraman ${ }^{1}$

${ }^{1}$ University of East Anglia

Professor Michael P Frenneaux, MD, FRCP, FRACP, FACC, FESC (Corresponding Author) Head of Norwich Medical School

Bob Champion Research and Education Building

James Watson Road

University of East Anglia

Norwich Research Park

Norwich NR4 7UQ

Tel: 01603592376

Email: M.Frenneaux@uea.ac.uk

Dr Nicholas D Gollop, MB BCh

MRC Doctoral Research Fellow in Cardiology

2.21c, Bob-Champion Research and Education Building

James Watson Road

University of East Anglia

Norwich Research Park

Norwich NR4 7UQ

Tel: 01603591790

Email: N.Gollop@uea.ac.uk

Dr Brodie L Loudon, MBBS

MRC Doctoral Research Fellow in Cardiology

2.21a, Bob-Champion Research and Education Building

James Watson Road

University of East Anglia

Norwich Research Park

Norwich NR4 7UQ

Tel: 01603591790

Email: B.Loudon@uea.ac.uk

Dr Sathish K Parasuraman, MRCP

BHF Cardiology Research Fellow

2.21d, Bob-Champion Research and Education Building James Watson Road

University of East Anglia

Norwich Research Park

Norwich NR4 7UQ

Ph. 01603591793

Email: S.Parasuraman@uea.ac.uk 
In the developed world there has been a substantial increase over several decades in the prevalence of congestive heart failure $(\mathrm{CHF})$, partly as a result of demographic changes. Overall, $1-2 \%$ of the adult population has CHF and this increases to $\geq 10 \%$ in the over 70 's (1). However, hospitalisation rates due to CHF are falling (2) and length of hospital stay and inhospital mortality have also fallen (3). It could be argued that effective outpatient management of CHF through dedicated heart failure clinics, specialist nurses and general practitioners has played a key role in these positive trends.

However, given the significant patient morbidity and the inpatient costs associated with CHF, methods to reduce hospital readmission rates are imperative to alleviate an already overstretched system. In this edition of the journal, Rahimi and Colleagues present the development and assessment of an easy-to-use, Android-based monitoring system to empower patients and reduce readmission rates in a cohort from the Seamless User-centred Proactive Provision Of Risk-stratified Treatment for Heart Failure (SUPPORT-HF) study. Patients were provided with Internet-enabled tablets which were connected to commercially available sensors to record blood pressure, heart rate and weight, and provide alerts to patients to see their doctor or health provider when physiological parameters were perturbed. Although this particular self-management study focused primarily on patient uptake of monitoring systems and did not offer any medical interventions beyond patient alerts to seek medical advice, the device was well received by patients and impressively, was reported as 'easy-to-use' in a cohort with a median age of 77 years and relatively little experience with digital systems. The tablets also provided access to educational materials for patients to view, including video clips about CHF and its management. This study presents an elegant yet simple method for patient monitoring and the findings indicate an underlying desire of patients to be involved in their own medical care.

Several forms of telemonitoring have been employed in CHF; remote patient telephone support, external monitoring devices, specialised implantable haemodynamic monitoring devices, and pre-existing device adaptation technologies. In a systematic review, Inglis et al. 
(2010) noted a reduction in risk of mortality and hospitalisation from CHF with the use of telemonitoring. Furthermore, a more recent meta-analysis by Pandor et al. (2013) showed a reduction in mortality in studies that used telemonitoring data to provide $24 / 7$ patient support. However critics point out that many of these studies had unblinded analysts, few participants, and only a moderate standard of methodological quality (4). More recently, the PatientCentred Disease Management (PCDM) for Heart Failure trial (2015) also failed to demonstrate a significant difference in health status with telemonitoring in heart failure patients.

Comparison of telemonitoring studies is complicated by the heterogeneity in the degree of contact with patients, and the ability to 'close the loop' between detection of perturbations in physiological parameters, notification of healthcare professionals, treatment, and assessment of treatment outcomes $(4,5)$. Most studies assessing treatments initiated in response to telemonitoring data have involved alterations in the doses of oral diuretics and organic nitrates; the feasibility of outpatient intravenous diuretic therapy is an avenue that requires further exploration.

New generation pacing and defibrillator systems are capable of measuring, storing and remotely transmitting heart rate, activity-level and intrathoracic impedance data. Decreased heart rate variability indicates autonomic imbalance with decreased cardiac vagal tone and increased sympathetic tone, and predicts CHF related hospitalisations days to weeks prior (6). A fall in patient activity levels might also give a clue to disease progression and may serve as a valuable educational tool for patients and their families to stress the importance of physical activity (7). A reduction in baseline intrathoracic impedance can identify increased fluid retention and increased LA filling (wedge) pressure, thus indicating possible decompensating CHF. Intrathoracic impedance devices may be limited however, by fluid accumulation within the path of the measurement area (such as oedema, inflammation or haematoma within the device pocket) or by intrathoracic processes such as pleural effusions or pneumonia (8). Intrathoracic impedance was shown to be superior to daily weight monitoring and predicts CHF decompensation 10-14 days in advance (9). The benefit of these potential advantages, 
however, has been inconsistently demonstrated in randomised trials $(10,11)$. Daily devicebased monitoring for tachyarrhythmias, increased intrathoracic impedance and reduced physical activity in the recent randomised, multi-centre IN-TIME trial (2014) in patients with implanted defibrillators, encouragingly showed a positive trend in mortality and hospital admissions in device-monitored patients. Developments in impedance cardiography (ICG), which allows for non-invasive measurement of intrathoracic impedance, have also shown positive results (12), however the data are not significant enough to supplant invasive measurements. Future research could explore these gaps in the evidence base.

Specialised implantable hemodynamic monitors (IHM) can measure right ventricular/estimated pulmonary artery pressure along with heart rate, temperature and activity level and are another exciting prospect. Initial studies have established safety of the devices and the results are encouraging. In the CHAMPION trial (2014), 550 patients with NYHA class III symptoms and a prior hospitalisation for CHF received a wireless implantable pulmonary artery pressure sensor and were randomised to treatment with or without the assistance of sensor data. At 6 months, there was a 30\% reduction in the primary end-point of CHF hospitalisations (HR $0.70,95 \% \mathrm{Cl}, 0.60-0.84, \mathrm{P}=0.0001)$. These data suggest that for selected patients with advanced CHF symptoms, continuous monitoring of intra-cardiac pressures may provide a reliable signal both for early detection of deterioration and for tracking effectiveness of early intervention that can facilitate improvements in clinical outcomes. Potentially, such additional data could help risk-stratify heart failure patients at high risk of sudden cardiac death.

\section{Conclusion:}

This study by Rahimi and Colleagues, assessing telemonitoring technologies in a cohort of patients from SUPPORT-HF, demonstrates an easy-to-use technological home-monitoring system that was well accepted by heart failure patients. Despite the fact that the verdict on previous telemonitoring technologies is still out, there are signs that this technology is improving rapidly and it looks like they will have a significant role in the optimal management 
of patients with $\mathrm{CHF}$ in the future. It is likely that the greatest promise lies with next-generation home monitoring systems, provided strategies are implemented for integrating them effectively into the healthcare framework to close the loop between patients and healthcare providers. 
1. McMurray JJ, Adamopoulos S, Anker SD, Auricchio A, Bohm M, Dickstein K, et al. ESC guidelines for the diagnosis and treatment of acute and chronic heart failure 2012: The Task Force for the Diagnosis and Treatment of Acute and Chronic Heart Failure 2012 of the European Society of Cardiology. Developed in collaboration with the Heart Failure Association (HFA) of the ESC. Eur J Heart Fail. 2012;14(8):803-69.

2. Braunwald E. Heart Failure. JACC: Heart Failure. 2013;1(1):1-20.

3. Mosterd A, Hoes AW. Clinical epidemiology of heart failure. Heart. 2007;93(9):113746.

4. Desai AS. Home Monitoring Heart Failure Care Does Not Improve Patient Outcomes: Looking Beyond Telephone-Based Disease Management. Circulation. 2012;125(6):828-36.

5. Konstam MA. Home Monitoring Should Be the Central Element in an Effective Program of Heart Failure Disease Management. Circulation. 2012;125(6):820-7.

6. Adamson PB, Smith AL, Abraham WT, Kleckner KJ, Stadler RW, Shih A, et al. Continuous autonomic assessment in patients with symptomatic heart failure: prognostic value of heart rate variability measured by an implanted cardiac resynchronization device. Circulation. 2004;110(16):2389-94.

7. Conraads VM, Spruit MA, Braunschweig F, Cowie MR, Tavazzi L, Borggrefe M, et al. Physical activity measured with implanted devices predicts patient outcome in chronic heart failure. Circ Heart Fail. 2014;7(2):279-87.

8. Wang L. Fundamentals of intrathoracic impedance monitoring in heart failure. Am J Cardiol. 2007;99(10A):3G-10G.

9. Abraham WT, Compton S, Haas G, Foreman B, Canby RC, Fishel R, et al. Intrathoracic impedance vs daily weight monitoring for predicting worsening heart failure events: results of the Fluid Accumulation Status Trial (FAST). Congest Heart Fail. 2011;17(2):51-5.

10. Landolina M, Perego GB, Lunati M, Curnis A, Guenzati G, Vicentini A, et al. Remote monitoring reduces healthcare use and improves quality of care in heart failure patients with implantable defibrillators: the evolution of management strategies of heart failure patients with implantable defibrillators (EVOLVO) study. Circulation. 2012;125(24):2985-92.

11. van Veldhuisen DJ, Braunschweig F, Conraads V, Ford I, Cowie MR, Jondeau G, et al. Intrathoracic impedance monitoring, audible patient alerts, and outcome in patients with heart failure. Circulation. 2011;124(16):1719-26.

12. Packer M, Abraham WT, Mehra MR, Yancy CW, Lawless CE, Mitchell JE, et al. Utility of impedance cardiography for the identification of short-term risk of clinical decompensation in stable patients with chronic heart failure. J Am Coll Cardiol. 2006;47(11):2245-52. 